\title{
Toddlers' Learning From Socially Meaningful Video Characters
}

\author{
ALEXIS R. LAURICELLA, ALICE ANN HOWARD GOLA, and \\ SANDRA L. CALVERT \\ Children's Digital Media Center, Department of Psychology, Georgetown University, \\ Washington, DC, USA
}

\begin{abstract}
Toddlers' performance on a seriation sequencing task was measured after exposure to a video as a function of the social meaningfulness of the character. Forty eight 21-month-old toddlers were randomly assigned to a socially meaningful character video demonstration, a less socially meaningful character video demonstration, or a no exposure control group. Results indicated that toddlers learned the seriation sequencing task better from a video when a socially meaningful character, rather than a less socially meaningful character, demonstrated the task. Our findings demonstrate that toddlers under age two can learn cognitive, logical reasoning skills from a video presentation when the onscreen character is socially meaningful to them.
\end{abstract}

Nearly $80 \%$ of toddlers view television or video programs, averaging two hours of screen time per day (Rideout \& Hamel, 2006). Although exposure to content on screens is pervasive, infants and toddlers learn better from a live rather than a video presentation (e.g., Barr \& Hayne, 1999; Kuhl, Tsao, \& Liu, 2003; Schmitt \& Anderson, 2002; Troseth \& DeLoache, 1998), a phenomenon known as the video deficit (Anderson \& Pempek, 2005). Nevertheless, very young children can learn from videos when simple actions are repeated (Barr, Muentener, Garcia, Fujimoto, \& Chavez, 2007), the video demonstration is lengthened (Strouse \& Troseth, 2008), the experimenter on the screen responds contingently to the child's actions via closed-circuit

Alexis R. Lauricella is currently a postdoctoral fellow in the School of Communication at Northwestern University, Evanston, Illinois.

Address correspondence to Sandra L. Calvert, Children's Digital Media Center, Department of Psychology, Georgetown University, 309 White Gravenor, 37th and O Streets, NW, Washington, DC 20057. E-mail: calverts@georgetown.edu 
television (Troseth, 2003), or the mother presents the onscreen task (Krcmar, 2010). Few studies, however, demonstrate infant and toddler learning from video beyond an exact reproduction of simple tasks (Anderson \& Pempek, 2005). This study examines whether toddlers can learn conceptual information from a video, and, if so, what conditions improve their learning.

\section{LEARNING FROM VIDEO}

Learning from a video is a difficult task for toddlers. More specifically, video is a symbolic medium in which toddlers must transfer symbolic twodimensional representations to real-world three-dimensional objects and situations (Barr, 2010; Troseth, 2010; Troseth, \& DeLoache, 1998). Most studies that examine toddlers' learning from screens use simple imitation tasks, object search tasks, or language learning (see Anderson \& Pempek, 2005, for review). To date, most studies demonstrate that young children experience a video deficit effect (see Anderson \& Pempek, 2005). None have studied how toddlers learn a logical-mathematical task from a video screen.

There are at least two possible nonexclusive explanations for why toddlers face difficulties when learning from video presentations. First, most videos created for infants and toddlers lack socially meaningful characters or social contingency (Krcmar, 2010), making it challenging for very young children to relate to the program or to recognize that they should be learning something from the onscreen content (Troseth, Saylor, \& Archer, 2006). Second, learning from videos requires very young children to process multiple aspects of the presentation simultaneously, such as the narration, the visual images, and the characters (Fisch, 2000). Processing each component of the presentation may be cognitively taxing for them (Barr, 2010).

\section{Social Meaningfulness of Video}

According to Troseth and colleagues (2006), very young children may fail to process video information because it lacks social relevance for them. More specifically, young children are accustomed to learning from social partners who respond contingently to them (Vygotsky, 1978). Therefore, very young children may learn to distrust information presented on videos because it lacks socially contingent replies, which, in turn, disrupts their learning from the video.

Krcmar (2010) divides Troseth's (2006) concept of social relevancy into two distinct parts: social meaningfulness and social contingency. She defines socially meaningful actors as familiar and meaningful in the sense that young children are likely to have learned from them in the past (e.g., mothers). 
Indeed, toddlers learned imitation tasks better when the onscreen character was socially meaningful (their mother) rather than a stranger (Krcmar, 2010), suggesting that social meaningfulness is important for early learning. Such an idea is consistent with the concept of parasocial relationships, an emotional one-way attachment that develops between an audience member and a media character (Horton \& Wohl, 1956). Children form emotional relationships with television characters (Hoffner, 1996, 2008), reporting that they "really like" certain popular television characters such as Dora from Dora the Explorer (Calvert, Strong, Jacobs, \& Conger, 2007). Additionally, using pictures of popular familiar characters, such as Elmo from Sesame Street, increased preschool-aged children's preference for foods that were being marketed (Kotler, Schiffman, \& Hanson, in press). As onscreen characters become socially meaningful to young children, they may become more likely to trust the characters, and therefore, learn the information that is being presented onscreen.

The second component of social relevancy is social contingency. Krcmar (2010) describes social contingency as the responsive replies (or the perception of responsive replies) to a child's actions. Television programs and videos designed for young children often have characters look directly at the audience through a camera lens, speak to the audience, pause for a reply, and then act as if the child has made a reply. Such character behaviors may engage a child in a communicative interaction that may be perceived as "real" or, at the very least, "realistic" (Calvert et al., 2007). Horton and Wohl (1956) defined a situation in which the audience members respond in some fashion to the actions and verbalizations made by the media character as a parasocial interaction. In fact, the more preschool-aged children participated with the character Dora from Dora the Explorer when she prompted them to respond "contingently" to her requests, the more they learned from her (Calvert et al., 2007). Similarly, toddlers learned information from a video when an onscreen experimenter spoke directly to them, using their name and other personal information (Troseth et al., 2006). This research demonstrates that experiences that are socially contingent via video can improve young children's learning from screen media.

Overall, then, both meaningful social relationships with media characters and social contingency with characters' actions may influence young children's behavior and their learning from video. Moreover, very young children may develop a socially meaningful relationship with a television character when that character engages in socially contingent interactions.

\section{Cognitive Demands of Video}

According to Fisch's (2000) capacity model, preschool-aged children have to allocate working memory to multiple areas when watching a television program to comprehend both the narrative and the embedded educational 
content, such as a lesson about the alphabet. Hence, well-developed educational programs attempt to make the educational lesson an integral part of the storyline, thereby reducing the strain on working memory capacities. Even during relatively easy video presentations, the working memory resources of very young children may be taxed when processing two competing kinds of information. Infants' performance on an imitation task, for instance, is impaired when a competing and potentially distracting musical sound track accompanies the video presentation (Barr, Shuck, Salerno, Atkinson, \& Linebarger, 2010), providing evidence that young children's working memory may be overloaded when required to process two separate components of a video simultaneously. This memory taxation may limit young children's ability to transfer what they see on a screen to real life (Barr, 2010).

Infants and toddlers may face similar challenges to working memory when they are simultaneously required to process a new character on the screen and the actions the character is demonstrating. Infants, for example, tend to focus their attention more often on faces rather than objects, even when watching cartoon characters on a screen (Frank, Vul, \& Johnson, 2009). Such findings suggest that toddlers may allocate their working memory resources to assess who a character is before they attempt to understand what that character is doing.

One possible remedy to the video deficit may be to increase prior knowledge of the video content or the character in order to reduce information processing demands. Research demonstrates that repeated exposure to a simple imitation task portrayed on a video, for example, can reduce the video deficit (Barr et al., 2007). Similarly, toddlers' learning of the novel word "crescent" improved after repeated exposure to a vignette labeling this shape (Vandewater, Barr, Park, \& Lee, 2010). Perhaps these benefits occur, in part, because the infant is becoming more familiar with the characters as well as the onscreen content with each repetition. In the current study, we expected that familiarity with an onscreen character may also decrease the working memory load, thereby enabling toddlers to focus on processing the task that was being portrayed on the video.

\section{LEARNING AND SERIATION SKILLS}

Viewing educational television programs during the preschool years, such as Sesame Street and Blue's Clues, benefits preschool-aged children's cognitive skills (see Wartella, Richert, \& Robb, 2010), including their math and school readiness scores at age five (Wright et al., 2001). Early educational media experience also has long-term cognitive benefits that continue into the adolescent years (Anderson, Huston, Schmitt, Linebarger, \& Wright, 2001). By 
contrast, research documenting any educational benefits of videos for infants and toddlers is rare.

Rule-governed skills lay a foundation for subsequent mathematical success. One such skill is seriation, an index of logical-mathematical thinking that develops during early childhood (Piaget, 1954; Siegel, 1972). In seriation tasks, objects are ordered by underlying conceptual properties, such as sequencing objects by size (Flavell, 1963).

Assessments of seriation performance provide a way to tap into important conceptual learning early in life. Previous research demonstrates that very young children can learn seriation tasks from live demonstrations (Fragaszy, Galloway, Johnson-Pynn, \& Brakke, 2002; Greenfield, Nelson, \& Saltzman, 1972). In these studies, an adult demonstrated how to nest, that is, seriate, five cups inside of each other in a face-to-face interaction with a very young child. By 21 months of age, some toddlers could seriate all five cups (Fragaszy et al., 2002; Greenfield et al., 1972). Although three- to five-yearold children can learn seriation skills from viewing a video (Henderson, Swanson, \& Zimmerman, 1975), research has not yet examined whether toddlers can learn this type of task from video. A seriation task lends itself nicely to the examination of whether toddlers can learn a cognitive skill from a video demonstration.

\section{THE PRESENT STUDY}

Our purpose here was to examine whether toddlers could learn a conceptual, seriation task from watching a video demonstration. To do so, we compared learning from a socially meaningful character on video to a less socially meaningful character on video and a no exposure control condition. The socially meaningful character was the popular and familiar puppet Elmo from Sesame Street, while the less socially meaningful character was the unfamiliar puppet DoDo (pronounced Dough Dough), a character popular in Taiwan but unknown to toddlers in the United States.

\section{Hypotheses}

H1: Toddlers in the socially meaningful character condition will be more likely to demonstrate social behaviors, such as smiling and saying the character's name, than those in the less socially meaningful character condition.

H2: Toddlers in the socially meaningful character condition will seriate more cups correctly than those in the less socially meaningful character condition or in the no exposure control condition. 


\section{METHOD}

\section{Participants}

Participants were 48 (24 males) 21-month-old toddlers ( $M=651.88$ days, $S D=17.31$, range $=566$ to 674 days) who lived in the Washington, DC, metropolitan area. Toddlers were recruited from a database of infants that had participated in previous studies, advertisements in newspapers, flyers in local businesses, and word-of-mouth communication with other parents. Parents' years of education ranged from 12 to 22 years $(M=17.99, S D=$ 1.84): $21 \%$ had 16 years or less of education (bachelor's degree or high school diploma) and 79\% had more than 16 years of education (master's degree or higher). Parents reported that their toddlers were Caucasian (79\%), Asian (6\%), African American (4\%), or of other or mixed ethnicities (11\%).

Equal numbers of boys and girls were randomly assigned to one of three conditions: the socially meaningful character (Elmo), the less socially meaningful character (DoDo), or a no exposure control. Three toddlers (1 male) who were randomly assigned to the socially meaningful character condition were not familiar with the Elmo character. We tested these toddlers because the questionnaire assessing familiarity with Elmo was given to the parent on the day of testing, and we did not know that they were unfamiliar with the character until we examined that data later. Because these toddlers did not meet the criteria of being familiar with the character, we then replaced them with toddlers who were familiar with the Elmo character.

\section{Materials}

Plastic nesting cups. Five colorful plastic nesting cups were used in a seriation task. The cups varied in size. The smallest cup measured $3.65 \mathrm{~cm}$ in diameter and $6.19 \mathrm{~cm}$ in height. The largest cup measured $11.75 \mathrm{~cm}$ in diameter and $10.32 \mathrm{~cm}$ in height. The cups also varied in color from smallest to largest: (1) green, (2) purple, (3) orange, (4) pink, and (5) yellow. The same set of five nesting cups was used for all demonstrations and subsequent testing of seriation skills.

Treatment videos. Two videos were created to demonstrate the seriation task. The videos were identical except that puppets of two different children's television characters performed the demonstration. In the socially meaningful character video condition, the popular U.S. character Elmo performed the seriation task. In the less socially meaningful character video condition, the popular Taiwanese character DoDo performed the seriation task. Both of the videos were created in our lab. The same puppeteer manipulated both of the puppets so that the actions were the same across both videos. To keep the language consistent across the video conditions, the same voiceover was used for both of the videos. Both of the characters spoke in the third person 
and used a high-pitched intonation that is typical of Elmo. The language differed between the two videos only when the character referred to himself in the third person (saying Elmo or DoDo, respectively).

Both of the characters used parasocial interaction techniques to introduce themselves to the audience (e.g., "Hi, my name is Elmo/DoDo!"), ask the audience questions (e.g., "Will you play with Elmo/DoDo?"), make eye contact with the audience, and give the audience positive verbal feedback (e.g., "Thank you! You good helper!"). Put another way, both of the character's actions were socially contingent to get the toddlers to believe that the character was speaking and interacting directly with them.

The seriation task was presented on the video as follows. The character first showed the toddler all five cups nested inside each other (goal state) and said, "Look, we are going to put the cups together like this, see?" Next the character put the cups in a line from smallest to biggest. The character said, "First, we take the teeny tiny cup and put it here. Then we put this one here. Next we put this one here. Then we put this cup here. And last we take the really big cup and put it here."

Then the puppet placed each cup inside the other, using Greenfield and colleagues' (1972) subassembly method. That is, first the smallest cup (1) was placed in cup 2; then those two cups were placed in cup 3; then those three cups were placed in cup 4; and finally, these 4 cups were placed inside the largest cup (5). While demonstrating this procedure, the character said, "Now we are going to put the cups together. First, we take the teeny tiny cup and put it in this one. Then we take this cup and put it in this one. Then we take this cup and put it in this one. And last, we take all the cups and put them in the really big cup." The toddler was shown all five cups completely nested inside each other again as the character said, "See we put the cups together!" The complete demonstration was repeated a second time in both video conditions. Both video treatment demonstrations lasted approximately four minutes.

Parent report measures. Before the toddler viewed the video presentation or performed the seriation task, a parent completed two measures. One was a survey of their toddler's media use patterns, and the other was a measure of their toddler's productive language skills, the MacArthur Communicative Development Inventory Checklist (CDI) Level II (Fenson et al., 2000).

An 18-question survey assessed toddlers' media use, favorite television characters, knowledge of Elmo, experience playing with nesting cups, and general family demographic information. Parents answered questions about the frequency of their child's media use, including how often they watch Sesame Street, based on a 4-point Likert scale ranging from never to usually several times per week. Additional questions about their child's favorite television character were fill-in-the-blank style. For example, "Does your child have a favorite TV/video character" and "If so, who is their 
favorite character?" Questions addressing their child's knowledge of Elmo also included which Elmo toys and books they had and whether they knew who Elmo was. Finally, parents were given a list of 70 television programs and videos created for young children and asked to check which programs their child had watched.

The MacArthur CDI (Fenson et al., 2000) short-form is a parent-report measure of children's productive language skills. Parents check off which of the 100 words their child says. The total number of words the child said was summed and used as a measure of their child's expressive vocabulary. Parents of two children did not complete the MacArthur CDI form. Mean scores calculated from the entire sample were substituted for the missing data.

\section{Procedure}

Toddlers were visited in their homes at a time chosen by their parents. Parents read and signed an informed consent form and filled out the two parent report measures while the experimenters played with the toddler. Once the parent completed the paperwork and the toddler appeared to be comfortable with the experimenters, the study began. The parent remained in the room with the toddler for the entire study.

Toddlers in the two experimental conditions (socially meaningful character and less socially meaningful character) sat on their parent's lap approximately two feet from a laptop computer on which the video demonstration was shown. After the demonstration, the toddler was seated on the floor and given the five plastic cups in a random spatial array. The experimenter said, "Now it's your turn to play with the cups." Toddlers in the no exposure control group did not see the demonstrations. Instead, the experimenter placed the cups on the floor in front of the child and said, "These are cups for you to play with." All toddlers were given a total of two minutes to play with the cups. Sessions were videotaped for later coding.

\section{Coding}

Seriation performance. Coders watched the video of the test session and recorded the order of each complete set of seriated cups. A complete set was defined as the final set of cups nested together before the toddler disassembled it. Consistent with the procedures of DeLoache, Sugarman, and Brown (1985), a toddler did not get credit if he or she turned a cup upside down, began stacking rather than nesting the cups, or did both actions.

All complete sets were scored for seriation performance based on a two-part system (see Wright et al., 1984). First, one point was awarded for each smaller cup that was placed inside a larger cup. For example, three points were awarded for cup 1 and cup 2 in cup 3: 1 point for $(1<2)+2$ points for $(1<2$ and $2<3)$. Next, additional points were awarded for each 
cup that was in the exact correct sequential order. For example, cup 1 and cup 2 in cup $3=2$ additional points (i.e., cup 1 next to cup 2; cup 2 next to cup 3). The total points were summed to create a seriation score (e.g., $3+$ $2=5$ total points for the above example). The score from each toddler's best seriated set during a two-minute time frame was used in later analyses.

Twenty-one percent of the sample was double coded by two independent coders for reliability. The primary seriation coder was familiar with the experimental hypotheses and knew which condition the toddler was in. The secondary coder was familiar with the experimental hypotheses but was blind to the condition the toddler was in. Intraclass correlations for reliability were perfect at $r=1.0$.

Visual attention. Visual attention was coded from the videotapes as each toddler in the treatment conditions viewed the demonstrations. Coders used Noldus Observer software, which allows the coder to view the video frame by frame when coding. Children's attention was coded as "on the screen" or "off the screen." Visual attention was calculated as a proportion, by dividing the total amount of time attention was onscreen by the total length of the presentation. Twenty-one percent of the sample was double coded for reliability by two independent coders who were blind to the experimental hypotheses and to treatment condition. Intraclass correlations for reliability were $r=.72$, within the acceptable range of 0.7 to 1.0 (see McGraw \& Wong, 1996). The primary coder's scores were used for all analyses.

Behaviors. Toddler behaviors were coded from the videotapes as each toddler viewed the demonstration. Coders used Noldus Observer software to score the number of times that the child smiled and said the character's name. Twenty percent of the sample was double coded for reliability by two independent coders who were blind to the experimental hypotheses. However, because the audio track of the video introduced the character by name, coders were not blind to the condition when coding for smiling or whether the children said the character's name. Intraclass correlations for reliability were $r=.87$ for smiling and $r=.95$ for naming the character, within the acceptable range of 0.7 to 1.0 (see McGraw \& Wong, 1996). The primary coder's scores were used for all analyses.

\section{RESULTS}

\section{Descriptive Statistics}

Reports from the parent questionnaire indicated that $90 \%$ of toddlers in the sample were familiar with Elmo and $88 \%$ had nesting cups at home. Eightyseven percent of the toddlers watched television and $84 \%$ of them viewed videos. There were no significant differences in children's media exposure, cup ownership, whether they knew of Elmo, or how much they liked Elmo 
by condition. As seen in Table 1 , the proportion of toddlers' visual attention in the treatment groups was very high $(M=.86, S D=.14$ for Elmo; $M=.91$, $S D=.14$ for DoDo) and did not significantly differ by condition. Language scores for toddlers in this sample ranged from 3 to 99 words, with an overall mean at 47.00 words $(S D=24.32)$. Scores on the MacArthur CDI did not significantly differ by condition. See Table 1.

Our first hypothesis was that toddlers in the socially meaningful character condition would be more likely to demonstrate social behaviors, such as smiling and saying the character's name, than would those in the less socially meaningful character condition. Consistent with the idea that toddlers form socially meaningful relationships with familiar characters, chi-square analyses revealed that significantly more toddlers in the socially meaningful character condition (100\%) smiled during the demonstration than toddlers in the less socially meaningful character condition $(69 \%), \chi^{2}(1, N=32)=5.93, p=.02$. More toddlers in the socially meaningful character condition (50\%) also said the character's name than toddlers in the less socially meaningful character condition $(6 \%), \chi^{2}(1, N=32)=7.58, p<.01$. See Table 1.

Because Pearson product moment correlations indicated that owning nesting cups, the biological sex of the toddler and visual attention did not significantly correlate with seriation scores, these variables were not included in subsequent analyses. Pearson product moment correlations indicated a significant relationship between MacArthur CDI language scores and seriation scores $(r=.32, p=.03)$. Therefore, language scores were included as a covariate in the remaining analyses. Because more children smiled and said the character's name while watching the socially meaningful character video than during the less socially meaningful character video, we conducted a second analysis of covariance (ANCOVA) for the two treatment conditions that controlled for language scores, whether the child smiled during the demonstration, and whether the child said the character's name during the demonstration.

TABLE 1 Prior Cup Exposure, Mean MacArthur CDI Scores (SD), Mean Visual Attention (SD), Smiling, Character Recognition, and Adjusted Mean Seriation Scores (SE) by Condition

\begin{tabular}{lccc}
\hline & $\begin{array}{c}\text { Elmo } \\
(n=16)\end{array}$ & $\begin{array}{c}\text { DoDo } \\
(n=16)\end{array}$ & $\begin{array}{c}\text { Control } \\
(n=16)\end{array}$ \\
\hline Number of toddlers who own cups & 14 & 15 & 13 \\
Mean MacArthur CDI score $(S D)^{\mathrm{a}}$ & $49.88(27.28)$ & $49.00(25.75)$ & $42.14(20.23)$ \\
Mean visual attention $(S D)$ & $.86(.14)$ & $.91(.14)$ & $\mathrm{N} / \mathrm{A}$ \\
Number of toddlers who smile during video & 16 & 11 & $\mathrm{~N} / \mathrm{A}$ \\
Number of toddlers who say character & 8 & 1 & N/A \\
$\quad$ name during video & $10.49(.97)$ & $7.47(.96)$ & $6.55(.97)$ \\
\hline Mean seriation scores & & &
\end{tabular}

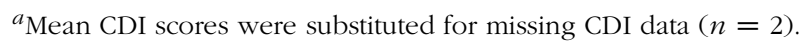

${ }^{b} \mathrm{CDI}$ scores were used as a covariate for seriation scores. 


\section{Seriation Performance}

Our second hypothesis was that toddlers in the socially meaningful condition would seriate more cups successfully than toddlers in the less socially meaningful condition or the no exposure control condition. A one-way ANCOVA controlling for toddlers' language scores was conducted with seriation scores as the dependent variable and condition (socially meaningful character, less socially meaningful character, no exposure control group) as the independent variable. Children's language scores emerged as a significant covariate, $F(1,44)=4.37, p=.042, \eta^{2}=.09$. There was also a significant main effect of condition, $F(2,44)=4.52, p=.016, \eta^{2}=.17$. As predicted, follow-up simple contrast comparison analyses revealed that toddlers in the socially meaningful character condition performed significantly better on the seriation task $(M=10.49, S E=.97)$ than did those in the less socially meaningful character condition $(M=7.47, S E=.96), p=.03$, or the no exposure control group $(M=6.55, S E=.97), p<.01$. The less socially meaningful character condition and the control group were not significantly different from one another. See Table 1 for the adjusted mean seriation scores. Interestingly, the three toddlers who were dropped from the socially meaningful character condition because they did not know the Elmo character had a similar mean (Unadjusted $M=8.00, S D=5.29$ ) as the unadjusted mean of those in the less socially meaningful condition $(M=7.56, S D=2.96)$.

A second ANCOVA controlling for language scores, whether the child said the character's name and whether the child smiled during the demonstration was used to compare the seriation scores between the socially meaningful character and the less socially meaningful character conditions. The covariate of smiling was significant, $F(1,27)=9.69, p<.01, \eta^{2}=.26$, and the language covariate emerged as a trend, $F(1,27)=3.35, p=.08$. As predicted, there was also a significant main effect of condition, $F(1,27)=11.70$, $p<.01, \eta^{2}=.30$. Toddlers who viewed the socially meaningful character demonstration performed significantly better on the seriation task (Adjusted $M=11.62, S E=.95)$ than those who viewed the less socially meaningful character demonstration (Adjusted $M=6.57, S E=.95$ ). In other words, even after controlling for the positive effects associated with emotional, motivational, and cognitive factors (i.e., smiling and language skills), the Elmo demonstration still increased children's learning beyond that of the DoDo demonstration.

\section{DISCUSSION}

The purpose of this study was to examine whether toddlers, prior to the age of two, can learn conceptual information from a video. As expected, 21month-old toddlers who viewed a video of the socially meaningful character 
Elmo as he demonstrated a task learned to seriate nesting cups significantly better than toddlers who saw no demonstration. However, toddlers who viewed the less socially meaningful character DoDo as he demonstrated the same task did not learn to seriate cups significantly better than toddlers who saw no demonstration. Our findings suggest that many studies of infant and toddler learning from videos, which rely on experimentally created stimuli using unfamiliar adults, may be underestimating what very young children can learn from onscreen characters.

As predicted, toddlers who viewed the socially meaningful character performing the seriation task also performed significantly better than those who observed the less socially meaningful character. Krcmar (2010) separated the concept of social relevancy (see Troseth et al., 2006) into two separate dimensions: social contingency and social meaningfulness. In our study, we held social contingency constant by having both characters use the same parasocial interaction techniques in the videos. These interactions with the viewers included making eye contact with the audience, asking viewers to play with them, and giving viewers positive feedback. If socially contingent actions were the underlying reason for learning, then performance should have been similar in both conditions. That was not the case here.

We varied social meaningfulness by manipulating whether the toddlers knew the character demonstrating the task or not. The superior performance of the toddlers in the socially meaningful character condition suggests that social meaningfulness is a key reason that very young children learn from videos (see also Krcmar, 2010). In Krcmar's (2010) study, children learned significantly better from mothers than from strangers. Mothers are both familiar and meaningful to their children in that they have played active roles in their child's learning before. Likewise, Elmo is a character that very young children are typically familiar with and a character who has taught them lessons via television in the past. As a result, young children may be primed to learn a lesson from Elmo who is socially meaningful to them, but not from DoDo who is less socially meaningful to them. This interpretation of the data is bolstered by the significant effect of the socially meaningful character over the socially less meaningful character on seriation performance, even when controlling for smiling, saying the character's name, and language scores.

Toddlers who saw Elmo perform the demonstration were more likely to smile and say the character's name than those who saw DoDo. This finding provides evidence that Elmo is a socially meaningful character to these toddlers. Moreover, smiling during the demonstration was a significant predictor of toddlers' improved seriation performance. These findings suggest that toddlers' emotional feelings about the characters or about the characters' actions improve their learning, in part because they may have developed an emotionally tinged parasocial relationship with the character (see Horton \& Wohl, 1956). 
Smiling is an indicator of positive emotions that has also been measured in infants as a proxy for interest or motivation when it is contiguous with successful performance (e.g., Redding, Morgan, \& Harmon, 1998). To examine if toddlers in our study were simply more motivated to complete the seriation task when they saw a socially meaningful character perform it on video, we controlled for smiling and saying the character's name in our analyses of the two treatment conditions. Because we did not always film the toddlers' faces while they were completing the seriation task, our measure for smiling took place when toddlers were viewing the videos. Although this is a limitation, the task did take place immediately after viewing. Moreover, we controlled for children's persistence, also a proxy for motivation (see Redding et al., 1998), by limiting the amount of time the toddlers could work on the task. Even when controlling for variables like smiling and persistence that often are associated with motivation, toddlers performed the task better when they saw a socially meaningful character than when they saw a less socially meaningful character demonstrate the task. Although the results are not definitive, they suggest that toddlers in the socially meaningful condition were not simply more motivated to complete the task, but that they did in fact learn more from the socially meaningful character.

Another possible interpretation of our findings involves the cognitive load required to process a cognitive lesson and an onscsreen character simultaneously. Young children may be trying to interpret who the novel character is, thereby deploying the majority of their attentional resources to understand the identity of the character rather than focusing on understanding what that character is doing. Such an interpretation is consistent with Fisch's (2000) capacity model in which children's working memory is divided between processing the story narrative and the embedded educational content. Similarly, when toddlers view videos, there may be competition for attentional resources between processing who the character is, as indexed by facial processing, and what the character does, as indexed by processing the character's behavior. When the character is socially meaningful to toddlers, as in the case of Elmo, less working memory may be needed to process the character and, thus, more working memory can be devoted to master the seriation task. Conversely, when a toddler is watching a demonstration performed by an unfamiliar character, as in the case of DoDo, their working memory may be directed at processing the novel face of the character at the expense of learning the task. Indeed, the mean seriation scores of the three toddlers who were dropped from the Elmo condition because they did not know him were similar to those of the toddlers who viewed DoDo, a character who was unfamiliar to U.S. toddlers. Overall levels of attention to the videos were similar in both treatment conditions, but we did not have eye-tracking data to pinpoint exactly where toddlers were looking on the screen. Eye-tracking studies, therefore, are an important area for future research that can shed light on this possible interpretation of the data. 
Repetition is one way that very young children learn a task presented on a video screen. For instance, infants who viewed a video demonstration of an adult putting a rattle together several times learned how to assemble the rattle as well as children who saw one demonstration performed in a faceto-face interaction (Barr, Muentener, et al., 2007). Similarly, children learned the word crescent prior to the age of two through repeated exposures to a commercially made video that labeled the shape (Vandewater et al., 2010). Repeated exposure to the same episode of the children's program Blue Clues also improved preschool-aged children's learning of content (Anderson et al., 2000; Crawley, Anderson, Wilder, Williams, \& Santomero, 1999). Perhaps repetition aids learning, in part, because the character performing the tasks becomes more socially meaningful to the child with each repetition. Consistent with this theory, toddlers who had prior experience with the Elmo character learned more than toddlers who did not have prior experience with DoDo. Given that more than $80 \%$ of the toddlers in our sample view videos at home, and that most toddlers view screen media approximately two hours per day (Rideout \& Hamel, 2006), one way to reduce the video deficit may well be through repeated exposure to specific educational content.

A key limitation of this study is that we were unable to measure how socially meaningful the Elmo character was for toddlers. Instead, we examined familiarity with Elmo as a proxy for social meaningfulness. Future research should separate very young children's familiarity with characters from the social meaningfulness of the relationships toddlers form with those characters in relation to their subsequent learning. Such a research approach might best be accomplished by exposing toddlers to an unfamiliar character over time. We also cannot speak directly to social meaningfulness as it relates to the video deficit because we did not compare socially meaningful and less socially meaningful live conditions to video presentations.

Additionally, when children were given the cups after watching the demonstration the experimenter simply said, "Now it's your turn to play with the cups." Since the children were not told to do what the model had done, it is possible that children in the less socially meaningful condition were less motivated to copy the character's behavior than those children in the socially meaningful condition. Thus, we cannot rule out that children who watched DoDo perform the task were not as motivated to perform the demonstrated activities as were the children who watched Elmo. Understanding how social meaningfulness, social contingency, familiarity, motivation, and engagement are related to the development of socially meaningful parasocial relationships and to the video deficit are important directions for future research.

Another study limitation involves our sample. The parents of our toddlers were very highly educated, which limits the generalizability of our findings, particularly given that better language skills, which are associated with higher education levels, were associated with better seriation skills. Other very young children may not learn as readily from screen exposure. 
Finally, toddlers only viewed a brief video clip, not a full-length 15- or 30minute video or television program. Therefore, it is unclear if these findings would remain the same in a more diverse sample or when toddlers view a typical video program.

In conclusion, toddlers can learn important cognitive seriation skills after viewing a video when a socially meaningful character demonstrates the task. Our results expand the concept of social meaningfulness from toddlers' learning from onscreen actions performed by their mothers (Krcmar, 2010) to actions performed by popular onscreen characters like Elmo that they view on a regular basis. As such, our findings support a viable ecological production practice that may potentially improve very young children's learning from a screen, an increasingly prevalent aspect of early twenty-first century experiences.

\section{ACKNOWLEDGMENT}

This research was supported by a grant from the National Science Foundation (NSF \#0126014) awarded to Sandra Calvert and by a Fred Rogers Memorial Scholarship awarded to Alexis R. Lauricella. We are grateful for their financial support. We also thank the parents and the children who participated in this research; Christine Baker, Marta Perrez, Monica Perrigino, Mollie Schmitz, and Alex Verdaguer for assisting in data collection and storing; Dr. Rusan Chen for assisting with statistical analysis; and Miss Sing-Ju Chang, Chief Executive of the Hsin Yu Foundation, for providing materials for this project.

\section{REFERENCES}

Anderson, D. A., Bryant, J., Wilder, W., Santomero, A., Williams, M., \& Crawley, A. M. (2000). Researching Blue's Clues: Viewing behavior and impact. Media Psychology, 2, 179-194.

Anderson, D. A., Huston, A. C., Schmitt, K., Linebarger, D. L., \& Wright, J. C. (2001). Early childhood television viewing and adolescent behavior: The recontact study. Monographs of the Society for Research in Child Development, 66(I, Serial No. 264).

Anderson, D. A., \& Pempek, T. A. (2005). Television and very young children. American Behavioral Scientist, 48, 505-522.

Barr, R. (2010). Transfer of learning between 2D and 3D sources during infancy: Informing theory and practice. Developmental Review, 30, 128-154.

Barr, R., \& Hayne, H. (1999). Developmental changes in imitation from television during infancy. Child Development, 70, 1067-1081.

Barr, R., Muentener, R., Garcia, A., Fujimoto, M., \& Chavez, V. (2007). The effect of repetition on imitation from television during infancy. Developmental Psychobiology, 49, 196-207. 
Barr, R., Shuck, L., Salerno, K., Atkinson, E., \& Linebarger, D. (2010). Music interferes with learning from television. Infant and Child Development, 19, 313-331.

Calvert, S. L., Strong, B. L., Jacobs, E. L., \& Conger, E. E. (2007). Interaction and participation for young Hispanic and Caucasian girls' and boys' learning of media content. Media Psychology, 9, 431-445.

Crawley, A. M., Anderson, D. R., Wilder, A. W., Williams, M., \& Santomero, A. (1999). Effects of repeated exposures to a single episode of the television program Blue's Clues on the viewing behaviors and comprehension of preschool children. Journal of Educational Psychology, 91, 630-637.

DeLoache, J. S., Sugarman, S., \& Brown, A. L. (1985). The development of error correction strategies in young children's manipulative play. Child Development, 56, 928-939.

Fenson, L., Pethick, S., Renda, C., Cox, J. L., Dale, P. S., \& Reznick, J. S. (2000). Short-form versions of the MacArthur Communicative Development Inventories. Applied Psycholinguistics, 21, 95-115.

Fisch, S. M. (2000). The capacity model of children' comprehension of educational content on television. Media Psychology, 2, 63-91.

Flavell, J. (1963). The developmental psychology of Jean Piaget. Princeton, NJ: Van Nostrand.

Fragaszy, D. M., Galloway, A. T., Johnson-Pynn, J., \& Brakke, K. (2002). The sources of skill in seriating cups in children, monkeys, and apes. Developmental Science, 5, 118-131.

Frank, M. C., Vul, E., \& Johnson, S. P. (2009). Development of infants' attention to faces during the first year. Cognition, 110, 160-170.

Greenfield, P. M., Nelson, K., \& Saltzman, E. (1972). The development of rulebound strategies for manipulating seriated cups: A parallel between action and grammar. Cognitive Psychology, 3, 291-310.

Henderson, R., Swanson, R., \& Zimmerman, B. (1975). Training seriation responses through television modeling of hierarchically sequenced rule components. American Educational Research Journal, 12, 479-489.

Hoffner, C. (1996). Children's wishful identification and parasocial interaction with favorite television characters. Journal of Broadcasting \& Electronic Media, 40, 389-402.

Hoffner, C. (2008). Parasocial and online social relationships. In S. L. Calvert \& B. J. Wilson (Eds.), The handbook of children, media, and development (pp. 309333). Malden, MA: Wiley-Blackwell.

Horton, D., \& Wohl, R. R. (1956). Mass communication and parasocial interaction. Psychiatry, 19, 215-229.

Kotler, J. A., Schiffman, J. M., \& Hanson, K. G. (in press). The influence of media characters on children's food choices. Journal of Food Health.

Krcmar, M. (2010). Can social meaningfulness and repeat exposure help infants and toddler overcome the video deficit. Media Psychology, 13, 31-53.

Kuhl, P. K., Tsao, F., \& Lui, H. (2003). Foreign language experience in infancy: Effects of short term exposure and interaction on phonetic learning. Proceedings of the National Academy of Sciences, 100, 9096-9101.

McGraw, K. O., \& Wong, S. P. (1996). Forming inferences about some intraclass correlation coefficients. Psychological Methods, 1, 30-46.

Piaget, J. (1954). The construction of reality in the child. New York, NY: Basic. 
Redding, R. E., Morgan, G. A., \& Harmon, R. J. (1998). Mastery motivation in infants and toddlers: Is it greatest when tasks are moderately challenging? Infant Behavior and Development, 11, 419-430.

Rideout, V., \& Hamel, R. (2006). The media family: Electronic media in the lives of infants, toddlers, preschoolers, and their parents. Menlo Park, CA: Henry J. Kaiser Family Foundation.

Schmitt, K. L., \& Anderson, D. R. (2002). Television and reality: Toddlers' use of visual information from video to guide behavior. Media Psychology, 4, 41-76.

Siegel, L. S. (1972). Development of the concept of seriation. Developmental Psychology, 6, 135-137.

Strouse, G. A., \& Troseth, G. L. (2008). "Don't try this at home”: Toddlers' imitation of new skills from people on video. Journal of Experimental Child Psychology, 101, 262-280.

Troseth, G. L. (2003). Getting a clear picture: Young children's understanding of a televised image. Developmental Science, 6, 247-253.

Troseth, G. L. (2010). Is it life or is it Memorez? Video as a representation of reality. Developmental Review, 30, 155-175.

Troseth G. L., \& DeLoache J. S. (1998). The medium can obscure the message: Young children's understanding of video. Child Development, 69, 950-965.

Troseth, G. L., Saylor, M. M., \& Archer, A. H. (2006). Young children's use of video as a source of socially relevant information. Child Development, 77, 786-799.

Vandewater, E., Barr, R. F., Park, S. E., \& Lee, S. J. (2010). A US study of transfer of learning from video to books in toddlers. Journal of Children and the Media, 4, 451-466.

Vygotsky, L. S. (1978). Mind in society: The development of higher psychological processes. Cambridge, MA: Harvard University Press.

Wartella, E., Richert, R. A., \& Robb, M. B. (2010). Babies, television and videos: How did we get here? Developmental Review, 30, 116-127.

Wright, J. C., Huston, A. C., Murphy, K., St. Peters, M., Pinon, M., \& Scantlin, R. (2001). The relations of early television viewing to school readiness and vocabulary of children from low-income families: The Early Window Project. Child Development, 72, 1347-1366.

Wright, J. C., Huston, A. C., Ross, R. P., Calvert, S. L., Rolandelli, D., Weeks, L. A., ... Potts, R. (1984). Pace and continuity of television programs: Effects on children's attention and comprehension. Developmental Psychology, 20, 653-666. 